\title{
GAIA Level 3 Assessment of Preterm Labor
}

National Cancer Institute

\section{Source}

National Cancer Institute. GAIA Level 3 Assessment of Preterm Labor. NCI Thesaurus. Code C127949.

GAIA Level 3 Assessment of Preterm Labor is defined by three criteria: first, confirmed delivery of a fetus between 24 0/7 and 36 6/7 weeks gestation; second, greater than four uterine contractions per hour as determined by clinical assessment; third, documented changes in cervical dilation or effacement during a two hour period. 